\title{
Survey of a venlo greenhouse by heavy snow hazard
}

\author{
Fengqi Zhu ${ }^{1, a}$ \\ ${ }^{1}$ Southeast University, Nanjing 210000, China \\ afengqizhu_seu@qq.com
}

Keywords: venlo greenhouse, heavy snow hazard, field inspection, structural identification. Abstract. During the spring festival in 2013, a venlo greenhouse was collapsed due to the heavy snow hazard occurred in the south of Jiangsu, China. The general process of inspection and identification of lightweight steel structure greenhouse was introduced according to investigation and analysis of collapse of the greenhouse. At last, the current problem of venlo greenhouse design and construction in our country is discussed, and a good reference of reasonable design and construction is provided for this type structure.

\section{Introduction}

Venlo style greenhouse, originated from a town named Venlo, is a dual-slope green house featured by easy installation, high transmittance, small-sectioned component, less steel spending, good sealing, large ventilated area, and high degree of industrialization. Venlo style greenhouse is broadly applied in the fields like aquaculture, seedling of flower and vegetables, production and buildings like ornamental greenhouse, eco-greenhouse restaurant, making it the most widely used greenhouse structure in the world. The greatest advantage of Venlo style greenhouse lies in its high transmittance. Roof of 26.5 inclination (maximum sunshine incidence) with reduced, shrunk sized component and small-sectioned aluminum alloy extrusions to replace components of light steel glass greenhouse has significantly decreased shading of the bearing component. When introduced to China, shade net is added at its top in order to adapt the climate here. Besides cooling system composed of fans and drenchers that are installed at interior house in summer; while in winter, heating system made up of a large number hot-water pipes and spread in the interior greenhouse is utilized to protect it from low temperature for non-stop production throughout the year. However, it is the light small-sectioned component that causes poor overload capacity. Therefore, accident is prone to appear when it is overwhelmingly overloaded. Meanwhile, the inside cooling and heating system of Venlo style greenhouse applied in China allows a considerable load for structure. As a result, there exists great potential safety hazard in China for greenhouse structure that is still designed according to specification of Venlo style greenhouse [1].

In recent years, China is frequently subjected to climate disaster. Snow hazard every time will inflict extensive damage on light-steel construction. Safety and quality identification keeps growing accordingly with the increasing number of Venlo style greenhouse. The damage of Venlo style greenhouse in snow hazard, generally speaking, is caused by overloaded snow and poor resistance. The damage forms are roughly divided into bended roof purlin, deformed or cracked roof slab; detached roof slab and prilin with non-collapsed framework, twisted or extracted steel column base; overall collapse of the construction resulting from gravely distorted steel truss, steel columns, purlins and wall beam $[2,3]$.

\section{Instance of engineering}

A flower culturing greenhouse, which is equipped with thin-film solar cell and grid-connected power station, has adopted self-controlled glass greenhouse of Venlo style with steel construction as its main body including truss, column, column brace, wall beam. The greenhouse, which will be completed by the end of 2010, shapes as triangle in its top and components like purlin, roof, gutter are made from 
aluminum alloy. The size of its plane axis is $132 \mathrm{~m} \times 64.1 \mathrm{~m}$ and the column axis $12 \mathrm{~m} \times 4 \mathrm{~m}$ folding back southwest. The layout of a total construction area of $800 \mathrm{~m}^{2}$ is presented as the chart, which is classified into A, B, C, D based on different size. Trusses, columns all employ Q235 steel with rectangle-shaped section bars and the roof, gutter, purlin 6063A-T5 aluminum alloy material with special section. The roof is equipped with solar panels and glass for the sake of power generation and lighting. NEN3859 and NPR3860 greenhouse standards of Dutch are taken as reference when designing the bearing capacity of the main structure. The main parameters: fundamental wind pressure of $0.44 \mathrm{KN} / \mathrm{m}^{2}$, reference snow pressure of $0.25 \mathrm{KN} / \mathrm{m}^{2}$, no less than twenty years of service life. A sudden blizzard rendered the greenhouse into collapse during Spring Festival in 2013.

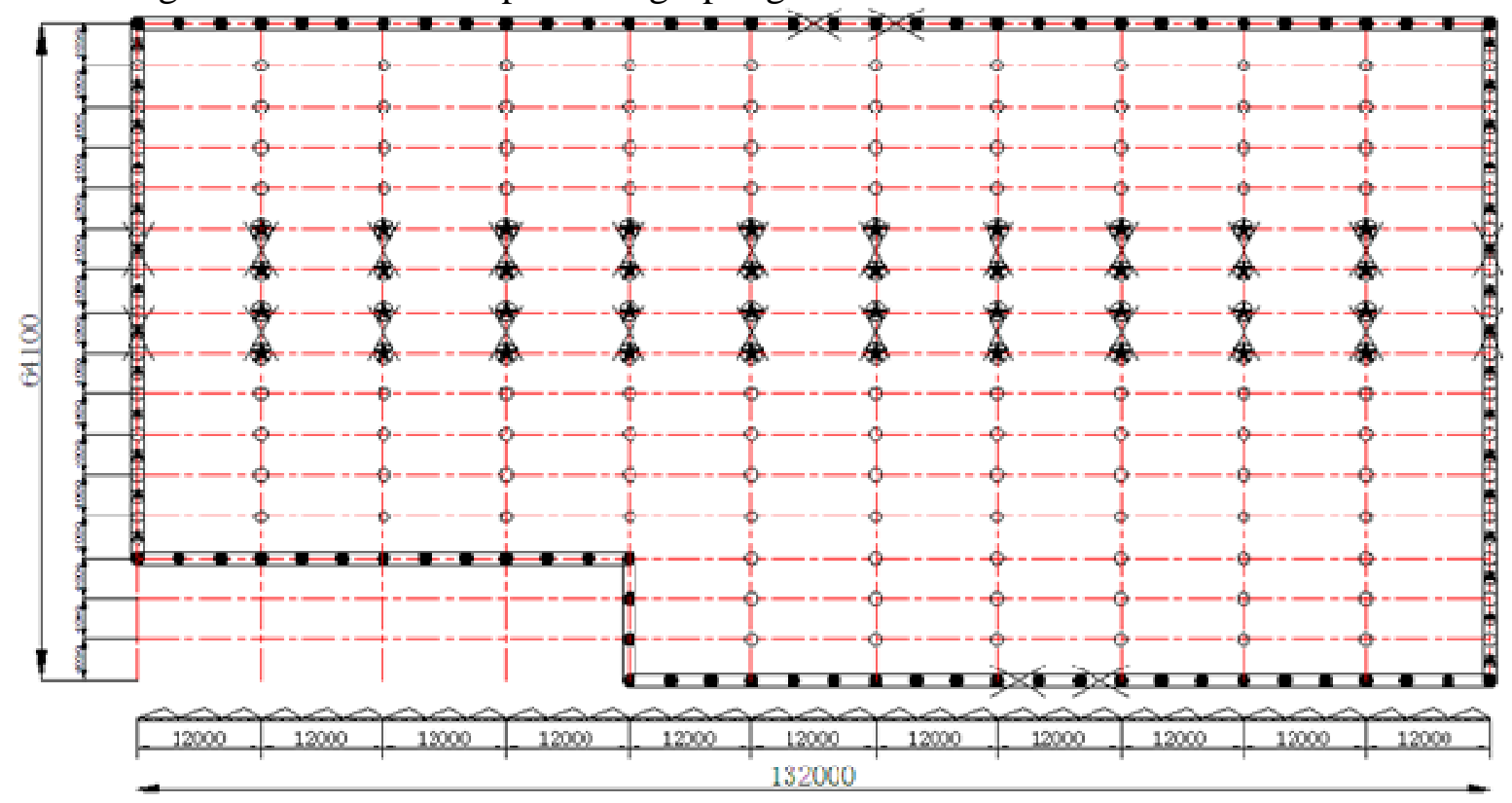

Figure1. layout of a venlo style greenhouse

\section{On-site test}

Reasons and failure forms are comprehensively investigated after collapse of the greenhouse; Radom inspection of geometry dimension of the major components in trusses, columns, roofs is conducted and its physical property is index-detected.

A. Damage forms of the structure

Judging from in-situ observation, the damage forms of the structure are mainly characterized with disabled stele base, out-of-plane stability of the upper and lower chord, yield failure of abdominal rod, inward collapse from a certain side with the side and middle spans falling successively to the other side as the consequences above features. And finally only an array of side span columns left behind as shown in Figure2 a, b.

Damage forms of the components: Two expansion bolts, which are connected with steel column base, are completely pulled out and broken (Figure $2 \mathrm{c}$ ); stele base is separate from concrete column and steels inside the concrete column are exposed after the foundation pillars crushing down due to the forces of stress (Figure2 d); column base and tailor-welded blanks are split at the welded side column bases which are jointed by two expansion bolts (Figure $2 \mathrm{e}$ ); The thickness of the concrete foundation arranges from $120 \mathrm{~mm}$ to $180 \mathrm{~mm}$ and it is shaped irregularly(Figure $2 \mathrm{f}$ ).

B. Inspection for column base and geometry dimension of the major components 


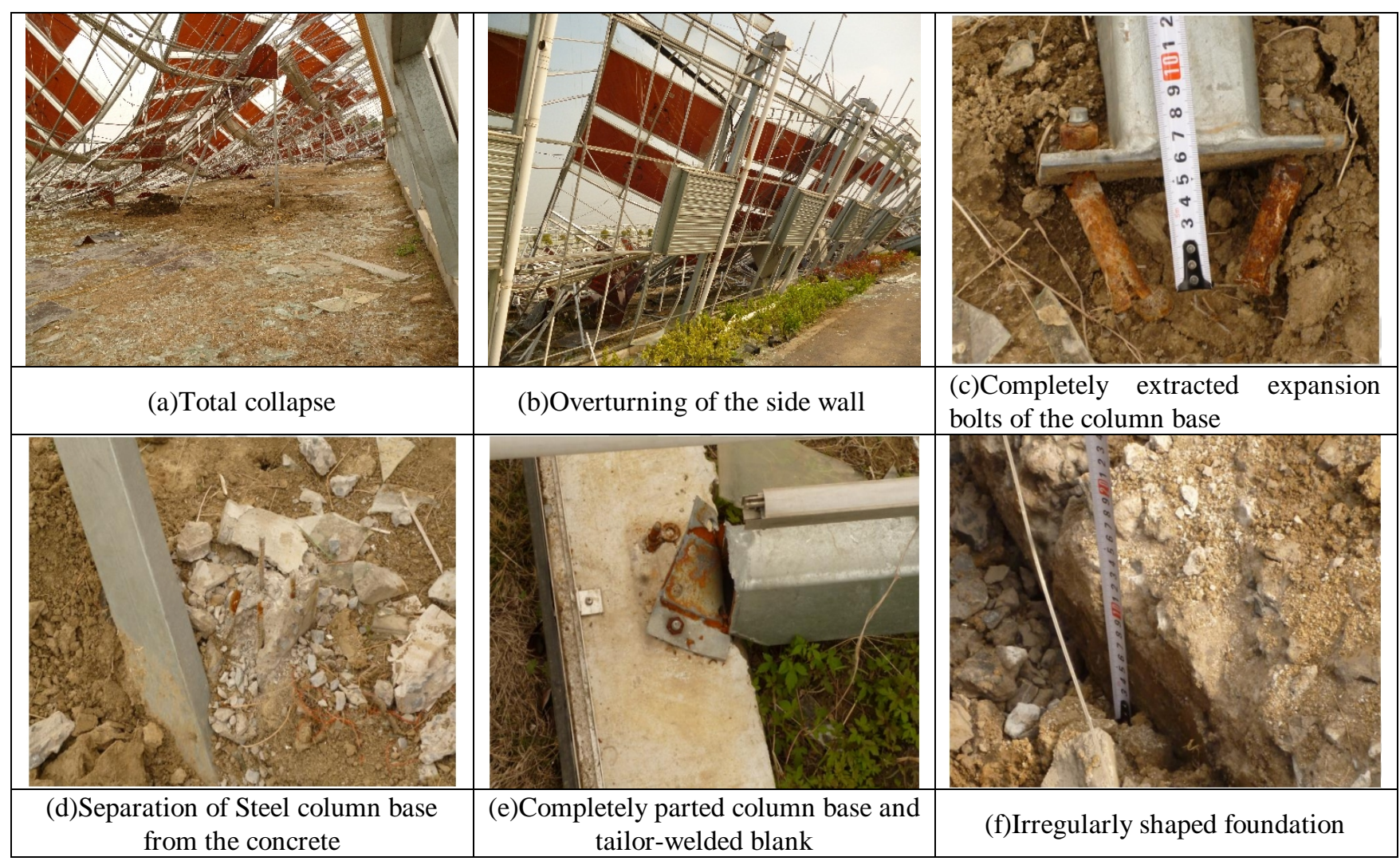

Figure2. damage forms of the site-inspection

Major components on the field are sampled and inspected randomly with vernier caliper to measure the dimension and thickness of two steel frames; so are the diameter, thickness, weight of the pipes in greenhouse. Undamaged solar panels are selected in the field to check their dimension, thickness, weight for randomly. The result as shown in the table1 finds the supporting round steel $\varphi 10$ of the columns inconsistent with original design. The result of random inspection of six columns shown in table 2 finds that there are no built-in fittings on the top of the ground beams and concrete columns, which risks column base with potential safety hazard.

\section{Physical property detection}

Physical property test of raw materials, which are cut from the major bearing components on the site like steel column, truss, aluminum alloy roof, are conducted after processing samples into standard specimen. Results of the detection (illustrated in the table 3) shows that material characteristics conform to the original design $[4,5]$.

Table1. geometry dimension of the components

\begin{tabular}{|c|c|c|}
\hline components & Dimension and size & Note \\
\hline Column a & Mouth of square pipe $160 \times 80 \times 4$ & Consistent \\
\hline Column b & Mouth of square pipe $140 \times 50 \times 3$ & Consistent \\
\hline Column C & Mouth of square pipe $140 \times 60 \times 3$ & Consistent \\
\hline Column E & Mouth of square pipe $140 \times 70 \times 6$ & Consistent \\
\hline column bracing & Round steel bar $\varphi 10$ & Inconsistent with $\varphi 12$ \\
\hline $\begin{array}{l}\text { Upper and Trussed beams of } \\
\text { upper and lower chords }\end{array}$ & Mouth of square pipe $60 \times 30 \times 2.5$ & Consistent \\
\hline $\begin{array}{l}\text { Heating system of pipes on the } \\
\text { wall }\end{array}$ & diameter $115 \mathrm{~mm}$; length $1000 \mathrm{~mm}$; weight $10.25 \mathrm{~kg}$ & unmarked \\
\hline Sprinkler system on the wall & diameter $40 \mathrm{~mm}$; length $1010 \mathrm{~mm}$; weight $1.47 \mathrm{~kg}$ & unmarked \\
\hline Solar panel & size : $1300 \times 1100 \times 7$; weight $23.40 \mathrm{~kg}$ & unmarked \\
\hline
\end{tabular}


Table2. column base

\begin{tabular}{|c|l|l|}
\hline Detected part & \multicolumn{1}{|c|}{ Result } & \\
\hline Column base A & 2M12anchored by expansion bolts to75mm & \\
\hline Column base A & $2 \mathrm{M} 12$ anchored by expansion bolts to $74 \mathrm{~mm}$ & $\begin{array}{l}\text { No built-in fittings are } \\
\text { found on the top of the } \\
\text { ground beams } \\
\text { concrete columns } \\
\text { and }\end{array}$ \\
\hline Column base C & $2 \mathrm{M} 10$ anchored by expansion bolts to $58 \mathrm{~mm}$ & \\
\hline Column base E & $1 \mathrm{M} 10$ anchored by expansion bolts to $60 \mathrm{~mm}$ & \\
\hline Column base E & $1 \mathrm{M} 10$ anchored by expansion bolts to $59 \mathrm{~mm}$ & \\
\hline
\end{tabular}

Table3. physical property of the components

\begin{tabular}{|c|c|c|c|}
\hline \multirow{2}{*}{ components } & tensile strength (Mpa) & yield strength (Mpa) & notes \\
\hline steel column & 466 & 382 & Q235 \\
\hline The top chord of truss & 418 & 343 & Q235 \\
\hline The bottom chord of truss & 435 & 388 & Q235 \\
\hline The middle brace rod of truss & 429 & 358 & Q235 \\
\hline Truss CHS & 490 & $/$ & Q345 \\
\hline purlin & 287 & $/$ & $6063 \mathrm{~A}$ \\
\hline ridge & 331 & $/$ & $6063 \mathrm{~A}$ \\
\hline gutter & 305 & $6063 \mathrm{~A}$ \\
\hline
\end{tabular}

\section{Conclusion}

1) The actual situation in China must be taken into consideration when introducing excellent foreign experiences. Overload claims the principal responsibility for this collapse by blindly coping the standard snow load of greenhouse in Dutch which is smaller than China's.

2 )Design must be strictly abided by during construction. Amount of expansion bolts in the column base are obviously cut down--- originally-designed six column bolts and foundation anchor are reduced to one or two in practice when building the greenhouse, which easily results in instability of pillars in large load.

\section{References}

[1] Shengning Lan, Xingu Zhong. Damage diagnose and lessons learnt from the failure of lightsteel structure by heavy snow in Xiangtan [J]. China Civil Engineering Journal, Vol.42 (3), 2009, p. 71-75.

[2] Feng Xue, Qing Chun. Inspection assessment and reinforcement design of a light steel plant building [J]. Architecture Technology, Vol.42 (4), 2011, p. 358-360.

[3] Ping Jiang. A case of structural identification of monolayer steel structure workshop [J]. Steel Structure, Vol.27 (5), 2012, p. 40-43.

[4] GB 50017-2003 Code for design of steel structures [S].

[5] GB/T 18622-2002 Greenhouse structure design load [S]. 